\title{
O novo constitucionalismo latino-americano e as inovações sobre os direitos da natureza na constituição equatoriana
}

\author{
Gustavo Silveira Borges ${ }^{1}$ \\ Marina Moura Lisboa Carneiro de Farias Carvalho²
}

\begin{abstract}
Resumo: A presente pesquisa pretende analisar o Novo Constitucionalismo latino-americano, movimento constitucional nascido nas terras ameríndias, tem como consequência as diversas modificações inseridas nas atuais Constituições de alguns países da América Latina, tais como a mudança de tratamento por parte do Estado Nacional aos grupos excluídos (índios, negros, afrodescendentes etc.), o reconhecimento da diversidade cultural, do pluralismo jurídico, de uma maior participação popular na resolução dos problemas sociais, entre outros. As Constituições que mais representam este novo constitucionalismo são os Textos Políticos do Equador (2008) e da Bolívia (2009). Referência para o novo constitucionalismo, a Constituição do Equador consagra o ecocentrismo em oposição ao antropocentrismo, uma vez que torna a natureza sujeito de direitos, garantindo o direito à sua restauração quando violada. Tal abordagem tem o intuito de responder se a positivação dos direitos da natureza na Constituição do Equador de 2008 será realmente eficaz na proteção e restauração dos danos ambientais? Neste cenário, objetiva-se com o presente trabalho compreender se a inovação trazida pela Magna Carta Equatoriana está sendo efetivamente cumprida. Concluiu-se, no entanto, que as decisões judiciais reconhecendo os direitos da natureza não foram integralmente acolhidas, apesar da relevância da temática. Na elaboração deste artigo, utilizou-se o método de abordagem dedutivo, mediante pesquisa bibliográfica.
\end{abstract}

Palavras-chave: Novo Constitucionalismo Latino-Americano. Constituição do Equador. "Buen Vivir". Direitos da Natureza. Rio Vilcabamba.

\section{The new latin american constitutionalism and the innovations on the nature rights in the ecuatorial constitution}

\begin{abstract}
The present research intends to analyze the New Latin American Constitutionalism, constitutional movement born in the amerindian lands, has as consequence the several modifications inserted in the present Constitutions of some countries of Latin America, such as the change of treatment by the National State to the excluded groups (Indians, blacks, Afro-descendants, etc.), recognition of cultural diversity, legal pluralism, greater popular participation in solving social problems, among others. The Constitutions that most represent this new constitutionalism are the Political Texts of Ecuador (2008) and Bolivia (2009). Reference to the new constitutionalism, the Constitution of Ecuador consecrates ecocentrism in opposition to anthropocentrism, since it makes nature subject to rights, guaranteeing the right to its restoration when violated. Does this approach aim to answer whether the positive nature of the 2008 Constitution of Ecuador will really be effective in protecting and restoring environmental damage? In this scenario, it is objected with the present work to understand if the innovation brought by the Magna Carta Ecuatoriana is being effectively fulfilled. It was concluded, however, that judicial decisions recognizing the rights of nature were not fully accepted, despite the relevance of the issue. In the elaboration of this article, the method of deductive approach was used, through bibliographical research.
\end{abstract}

Keywords: New Latin American Constitutionalism. Constitution of Ecuador. "Good Living". Rights of Nature. Vilcabamba River.

\section{Introdução}

No século XXI, em solo ameríndio, desenvolveu-se um novo modelo de constitucionalismo, o chamado "Novo Constitucionalismo latino-americano". Dentre os seus principais objetivos, destaca-se a proposição de uma verdadeira ruptura com a perspectiva moderno/colonial eurocêntrica 
que dominou, e ainda sufoca, a população da região por muitos e muitos séculos. Tal concepção constitucional eurocêntrica submete o povo à condição de escravidão, exclusão e subalternização a partir da proposição de categorias "universais" a serem impostas a todas as Constituições do planeta com pretensões universais e comuns a todos. Para tanto, tal movimento constitucionalista propõe uma reformulação do Estado Nacional, aproximando grupos excluídos, como: índios, negros, afrodescendentes etc., das decisões políticas, reconhecendo o pluralismo jurídico, ampliando os direitos coletivos, dentre outras proposições de proteções jurídicas constitucionais diferenciadas da perspectiva colonial universal.

Além das significativas mudanças de caráter democrático, a Constituição do Equador de 2008 pode ser considerada como uma das principais referências do novo constitucionalismo, uma vez que institucionalizou e positivou o modelo ecocêntrico, em oposição ao antropocentrismo, atribuindo direitos a "Pachamama" (direitos da natureza), que deve ser restaurada e, sobretudo, preservada do sofrimento de danos ambientais. Para análise da questão central envolvendo o tema, buscar-se-á responder a seguinte indagação: a positivação constitucional da natureza como sujeito de direitos na Constituição do Equador de 2008 será realmente eficaz na proteção e restauração dos danos ambientais?

Nesse contexto, objetiva-se, com o presente trabalho, compreender se a inovação trazida pela Constituição Equatoriana de 2008, de atribuição de direitos à natureza, está sendo efetivamente cumprida, com sua plena reabilitação e restauração da natureza quando violada, trabalhando-se a partir do caso concreto do Rio Vilcabamba.

Para isso, foram estabelecidos três objetivos específicos para o desenvolvimento do presente artigo. O primeiro, será o de analisar o surgimento e desenvolvimento do Novo Constitucionalismo na América Latina e, em especial, na Constituição do Equador de 2008.

O segundo objetivo, examinar a atribuição de direitos à "Pachamama", analisando os dispositivos da Constituição Equatoriana de 2008 (art. 71 a 74), os quais consagram a natureza como detentora de personalidade jurídica e o instituto do "buen vivir".

Por fim, o terceiro objetivo será analisar a restauração do dano ambiental no Equador, a partir do primeiro processo judicial em que a natureza figurou como parte, conhecido como caso do "Rio Vilcabamba".

O assunto é de extrema importância, pois dignidade e direitos eram reservados, até então, somente aos seres humanos, ainda predominando uma visão antropocêntrica da realidade. A consagração jurídica de que a natureza é, em verdade, um ser dotado de subjetividade e possui, pois, dignidade e direitos, visa a estimular a consciência ecológica, para que se tenha um desenvolvimento sustentável. Diante desse cenário, a relevância da pesquisa é alertar para a urgência e atualidade do enfrentamento do tema.

$\mathrm{Na}$ elaboração deste artigo, utilizou-se o método descritivo/qualitativo, mediante pesquisa bibliográfica consistindo na leitura de várias obras e artigos científicos a respeito do tema.

A "Pachamama" é vista como uma fonte de renda inesgotável, apesar de seus recursos serem finitos. Há quase meio século, cientistas vêm alertando sobre os perigos da continuidade do modelo de dominação existente dos seres humanos sobre a natureza. É com base neste cenário que o Novo Constitucionalismo desponta a coragem de propor uma mudança paradigmática, por meio 
de um giro ecocêntrico, exaltando e preservando a natureza como sujeito de direitos, como se verá adiante.

\section{O novo constitucionalismo latino-americano}

\section{Contextualização histórica do novo constitucionalismo latino-americano:}

É nas terras ameríndias, no século XXI, que nasce o Novo Constitucionalismo latino-americano. Os principais Textos Políticos em que se manifestam são as Constituições do Equador (2008) e da Bolívia (2009). Seus traços dominantes podem ser expostos na interculturalidade, na plurinacionalidade e no pluralismo jurídico.

Os Estados-Nação formados na América Latina, a partir do século XIX, tinham como principal característica terem sido pensados para uma pequena parcela da sociedade: homens brancos descendentes de europeus. A maior parte da população, formada pelos povos indígenas e pelos afrodescendentes, não era considerada parte do Estado e, portanto, excluídos (FURNALETTO, 2014 , p. 28). O extermínio da cultura e de todas as características dos povos ameríndios foi praticado pelos colonizadores europeus logo em sua chegada ao território latino-americano, na busca de soluções para seus problemas financeiros. O respeito e a convivência harmônica com a natureza foram substituídos pela exploração da mesma, em nome do crescimento econômico.

Este fenômeno, denominado de "modernidade", teve seu início com a afirmação do Estado unitário no continente Europeu, alcançando seu ápice com a invasão e colonização do continente latino-americano por parte do "homem branco europeu". A colonização do povo ameríndio teve como fundamento a visão eurocêntrica de mundo, preocupada apenas com o desenvolvimento econômico das nações, gerou uma classe de "excluídos", sujeitos que historicamente foram oprimidos e nunca tiveram qualquer poder decisório perante o espaço público (WOLKMER; LUCAS, 2013, p. 333-334).

Sobre a dominação europeia na América, Enrique Dussel apresenta a Filosofia da Libertação. Para o autor, o mundo é dividido em duas partes: o centro, ocupado pela Europa; e a periferia, posição dos países latino-americanos. O que deve predominar no mundo provém do centro: conhecimento, cultura, ciência, saber etc. Todo o restante deve ser oprimido, para que não se prolifere (FURNALETTO, 2014, p. 23). Ao tratar do "outro", Enrique Dussel mostra que, apesar de sua existência, ele nada significa. Esse "outro" é ocultado junto com a sua história, a sua cultura, a sua forma de vida, os seus valores. Segundo Dussel:

O outro, que não é diferente (como afirma a totalidade) mas distinto (sempre outro), que tem sua história, sua cultura, sua exterioridade, não foi respeitado; não se lhe permitiu ser outro. Foi incorporado ao estranho, à totalidade alheia. Totalizar a exterioridade, sistematizar a alteridade, negar o outro como outro é a alienação. Alienar é vender alguém ou algo; é fazê-lo passar a outro possuidor ou proprietário. A alienação de um povo ou indivíduo singular é fazer-lhe perder seu ser ao incorporá-lo como momento, aspecto ou instrumento do ser de outro. (DUSSEL, 1977, p. 58). 
Ao chegar ao continente latino-americano, os colonizadores europeus exterminaram a cultura e as principais características do povo indígena. A convivência harmônica entre o homem e a natureza foi abolida em prol do domínio da economia. Sob esses efeitos da colonização viveu a América Latina no século XIX até o surgimento do Novo Constitucionalismo cujo principal objetivo é a pretensão de reformulação do Estado, priorizando a diversidade cultural de seus povos, rompendo em definitivo com o colonialismo eurocêntrico (FURNALETTO, 2014, p. 23).

O Novo Constitucionalismo latino-americano é composto, segundo Raquel Z. Yrigoyen Fajardo, apenas pelas Constituições do Equador (2008) e da Bolívia (2009). Já para Rubén Martínez Dalmau, a Constituição da Venezuela (1999) também faz parte desse fenômeno. Referindo-se às três Constituições mencionadas, Dalmau declarou que:

As três Constituições formam parte de uma corrente conhecida como o "novo
constitucionalismolatino-americano". Trata-se,recolhendoa evoluçãodoconstitucionalismo
desde a sua aparição, no século 18, e em particular os avanços no constitucionalismo europeu
depois da Segunda Guerra Mundial, de avançar em âmbitos nos quais o constitucionalismo
europeu ficou paralisado: a democracia participativa, a vigência dos direitos sociais e dos
demais direitos, a busca de um novo papel da sociedade no Estado e a integração das
minorias até agora marginalizadas. Estamos diante de Constituições que, por um lado, são
originais e próprias de cada país, na medida em que tentam solucionar os problemas de
cada uma das sociedades onde serão implantadas. Mas, por outro lado, estamos diante de
denominadores comuns óbvios, principalmente no campo da participação, da economia e
de uma vigência efetiva dos direitos para todos. (MARTíNEZ DALMAU, 2017).

O novo constitucionalismo possui como principal característica a clara demonstração da soberania popular nas palavras de Roberto Viciano Pastor e Rubén Martínez Dalmau, os quais citam como primeiro exemplo o processo constituinte que resultou na Constituição da Colômbia de 1991. Para eles, a Constituição Colombiana é um divisor de águas, representando dois momentos distintos: um antes e um depois do constitucionalismo latino-americano. Outras Constituições também foram promulgadas seguindo essa linha, tais como: Equador (1998), Venezuela (1999) e Bolívia (2006 - 2007/2009). Porém, para os autores, o exemplo da Venezuela é o mais próximo do que viria a ser então denominado de Novo Constitucionalismo na América Latina (MARTÍNEZ DALMAU; VICIANO PASTOR, 2013, p. 50-54).

Adotando a classificação apresentada por Raquel Z. Yrigoyen Fajardo, Antônio Carlos Wolkmer afirma que apenas as Constituições do Equador e da Bolívia enquadram-se no Novo Constitucionalismo.

A partir da reformulação do Estado, parte-se para um novo constitucionalismo, bem diferente do constitucionalismo moderno. Segundo Boaventura de Sousa Santos, "é através da mobilização social e política que, no continente ameríndio, manifestam-se nas últimas décadas em nível constitucional os anseios populares, o que vem a caracterizar um constitucionalismo desde baixo, que é promovido por aqueles até então totalmente excluídos, à margem das decisões políticas" (SANTOS, 2010, p. 71-72). Conforme exposto, este novo constitucionalismo está intimamente ligado com a ideia de democracia, pois busca aproximar o povo das decisões políticas, ou seja, dar voz a classe dos "excluídos", que desde sua colonização pelos europeus carecia de qualquer poder decisório. Nesse sentido é a lição de Milena Petters Melo: 


\begin{abstract}
Nessa nova fase, conhecida também como "Constitucionalismo andino", os textos constitucionais são elaborados por assembleias constituintes participativas, sendo posteriormente objetos de aprovação popular por meio de referendum. As cartas constitucionais são mais amplas, complexas e detalhadas, radicadas na realidade históricocultural de cada país e, portanto, declaradamente comprometidas com os processos de descolonização. Ao mesmo tempo, as novas Constituições conjugam a integração internacional à redescoberta de valores, tradições e estruturas locais e peculiares, e estimulam, assim, um novo modelo de integração latino americana, de conteúdo marcadamente social, que supera o isolacionismo intercontinental de origem colonial e enfatiza a solidariedade nesse novo contexto da integração. (MELO, 2013, p. 144).
\end{abstract}

Ainda nas palavras dos professores Antônio Carlos Wolkmer e Lucas Machado Fagundes quanto a este recente modelo de institucionalidade, baseado nas diferenças e no diálogo entre as culturas,

(...) Pode-se caracterizar que este novo constitucionalismo de tipo plural e intercultural traduz um movimento popular de exigibilidade de uma nova "mirada política", com mudanças institucionais profundas, um constitucionalismo que vem das bases e é por esta influenciado, um "constitucionalismo desde abajo"; no qual o poder constituinte popular se sobrepõe ao poder constituído (...). Compõem-se numa manifestação política popular, participativa e atuante de diversos setores, alguns historicamente marginalizados e isolados por um pensamento e prática político-jurídica eurocêntrica. (WOLKMER; FAGUNDES, 2013, p. 339).

Da análise do acima exposto, pode-se concluir que o movimento emergiu da necessidade histórica de se garantir, através da positivação constitucional, alguns instrumentos de lutas e reivindicações de movimentos sociais de toda América Latina, visando, assim, ao maior controle popular sobre as políticas públicas. Esse cenário resultou na promulgação de diversas constituições, entre elas a Constituição do Equador em 2008, que será tratada no próximo tópico.

\title{
Os aportes do Novo Constitucionalismo no Equador
}

A partir do estudo da Constituição Equatoriana (2008), é possível extrair as principais características ancoradas pelo Novo Constitucionalismo: a interculturalidade, a plurinacionalidade e o pluralismo jurídico. É no texto constitucional também que se verifica, pela primeira vez na história, a positivação dos direitos a natureza (ecocentrismo).). Tal fato proporcionou uma ruptura com os valores antropocêntricos antes dominantes.

Tratando-se, em breve relato, das principais características do recente movimento constitucional, extrai-se do pensamento de Ramiro Ávila Santamaría, que a interculturalidade quer dizer o contato e o intercâmbio entre diferentes culturas, bem como a igualdade de tratamento de cada uma delas. Não se pode afirmar que uma cultura seja melhor do que a outra. Quando isso ocorre, verifica-se a presença da hierarquização entre os povos, da prevalência da cultura hegemônica (ÁVILA SANTAMARÍA, 2008, p. 216).

Interculturalidade pode ser entendida como um princípio dos movimentos indígenas, os quais buscam o reconhecimento e a aceitação de suas relações pessoais e com a natureza, de suas instituições, estruturas e características. Nas palavras de Raimon Panikkar, não pode haver uma única cultura, razão pela qual o autor esclarece que "la interculturalidad es inherente al ser humano y 
que una cultura única es tan incomprensible e imposible como una sola lengua universal y un hombre solo" (PANIKKAR, 2000, p. 96).

Como dito, uma das principais preocupações do novo movimento refere-se à questão da diversidade cultural. Para Agustín Grijalva, a variedade de culturas estará presente quando diversos grupos humanos aglomerarem-se em um mesmo território (pertencente a um único Estado), cada um deles com seus próprios costumes, língua, origens, etc. Quando o Estado reconhece a existência desta diversidade cultural em seu país, através de sua Constituição, é sinal de que aprendeu a conviver com esta diversidade, e que busca o intercâmbio e o diálogo entre as culturas, e não a dominação de uma delas sobre as demais (GRIJALVA, 2010, p. 153-154).

Pautada na democracia participativa e no diálogo dos povos "excluídos" surge o Estado plurinacional, igualitário, que respeita e valoriza as diversidades, superando o modelo até então existente e dominante, o Estado nacional. Com as recentes Constituições oriundas das revoluções, é na Bolívia e no Equador que se encontram os melhores exemplos de superação do Estado nacional.

O Estado plurinacional é aquele em que as pessoas que nele residem são consideradas nacionais pela identificação pessoal que possuem com este Estado e pelo simples fato de ali estarem (ÁVILA SANTAMARÍA, 2008, p. 195-197). Boaventura de Sousa Santos define plurinacionalidade nos seguintes termos: "la plurinacionalidad es una demanda por el reconocimiento de outro concepto de nación, la nación concebida como pertenencia común a una etnia, cultura o religión" (SANTOS, 2010, p. 81). Acerca do tema, lecionam José Luiz Quadros de Magalhães e Henrique Weil:

A ideia de Estado Plurinacional pode superar as bases uniformizadoras e intolerantes do Estado nacional, onde todos os grupos sociais devem se conformar aos valores determinados na constituição nacional em termos de direito de família, direito de propriedade e sistema econômico, entre outros aspectos importantes da vida social [...] A grande revolução do Estado Plurinacional é o fato de que este Estado constitucional, democrático participativo e dialógico, pode finalmente romper com as bases teóricas e sociais do Estado nacional constitucional e democrático representativo (pouco democrático e nada representativo dos grupos não uniformizados), uniformizador de valores e, logo, radicalmente excludente. (MAGALHÃES; WEIL, 2012, p. 108).

Em relação à característica do pluralismo jurídico, José Luiz Quadros de Magalhães conceitua o fenômeno como sendo a existência em uma mesma nação de mais de um sistema jurídico vigente. Para ele, essa é a principal novidade trazida pelo Estado plurinacional. Nestes termos diz que

(...) Enquanto as formas de organização territorial modernas (os Estados unitário, regional, autonômico e federal); o direito comunitário (a União Europeia) e mesmo o direito internacional são, na sua essência, modernos e, logo, uniformizadores, hegemônicos e europeus, a novidade do Estado plurinacional é a existência de um sistema plurijurídico marcado pela diversidade de direitos de família e de propriedade e da autonomia para resolver as controvérsias sobre estes temas em seus espaços territoriais pela sua própria justiça. Esta diversidade de sistemas jurídicos, de formas de organização econômica resulta de uma nova perspectiva democrática (a democracia consensual e uma justiça consensual - já vistos) e reforça a possibilidade de construção de espaços de convivências e diálogos de diversas formas de ver, sentir, compreender o mundo, de diversas epistemologias. Isto é riquíssimo para se repensar um direito mundial para além da modernidade europeia hegemônica e uniformizadora que influencia na construção do direito moderno e, logo, do direito internacional (MAGALHÃES, 2012, p. 105-106). 
A terceira característica diz respeito ao fenômeno do pluralismo jurídico, fenômeno que nasce dos complexos conflitos humanos presentes na atualidade, os quais não conseguem ser resolvidos a partir de uma concepção única e centralizadora do direito. Basicamente, o pluralismo jurídico pode ser entendido como a existência concomitante de dois ou mais sistemas jurídicos, todos dotados de ampla eficácia ou, nas palavras de Antônio Carlos Wolkmer como a "multiplicidade de manifestações ou práticas normativas num mesmo espaço sócio-político, interagidas por conflitos ou consensos, podendo ser ou não oficiais e tendo sua razão de ser nas necessidades existenciais materiais" (WOLKMER, 2008, p. 188).

Tradicionalmente, em um Estado de Direito, o único sistema jurídico válido é o estatal, ou seja, a lei é a única fonte de direito e tudo o que estiver fora dela não terá validade e não será considerado. Entretanto, no Estado Constitucional de Direito a visão do sistema jurídico é ampliada, e outras fontes de direito passam a ser consideradas, tais como os precedentes nacionais e internacionais, as políticas públicas emitidas pelo Poder Executivo com força de lei, o reconhecimento das normas das comunidades indígenas para a solução dos seus conflitos, entre outros. Isso tudo configura o pluralismo jurídico (ÁVILA SANTAMARÍA, 2008, p. 123-124) (grifo nosso).

De maneira inovadora, a Constituição do Equador de 2008 reconhece a justiça indígena e estabelece a mesma hierarquia em relação à justiça estatal. Segundo Boaventura de Sousa Santos, reconhecer a justiça indígena significa afirmar a diversidade cultural que existe no Equador, possibilitando a resolução de pequenos problemas dentro das próprias comunidades indígenas, rompendo, assim, com os vínculos eurocêntricos que nos últimos duzentos anos condicionaram o desenvolvimento neste território (SANTOS, 2012, p. 15). No entender de Antônio Carlos Wolkmer e Gabriela de Moraes Kyrillos,

(...) as inovações constitucionais são também uma valorização dos saberes, subalternizados e podem ser entendidas como espaços de poder de grande relevância a partir do qual os povos indígenas conseguiram inserir sua filosofia e cosmovisão sobre o mundo e a natureza, e revelam alternativas às crises que a modernidade criou e que ela mesma é incapaz de solucionar sem repensar suas lógicas e padrões de pensamento e de interação com o outro - seja ele humano ou não humano (WOLKMER; KYRILLOS, 2015, p. 134).

A incorporação da cosmovisão indígena no texto constitucional equatoriano trouxe consigo o reconhecimento de dois inovadores princípios: o Buen Vivir e a natureza enquanto sujeito de direito, situação esta que impõe mudanças na interpretação e na prática jurídica. Surge, assim, um movimento de luta pela liberdade da natureza, que não deve ser explorada e dominada para uso exclusivo e ilimitado dos seres humanos. É chegada a hora de a humanidade reconhecer a insustentabilidade do atual desenvolvimento que visa apenas ao crescimento econômico e promover os direitos da natureza.

Uma vez aplainados os conceitos acerca do constitucionalismo latino-americano, tratar-se-á detidamente acerca do Buen Vivir e a natureza enquanto sujeito de direito. 


\section{Pachamama, Buen vivir e Sumak Kawsay: a natureza na constituição do Equador (2008)}

\section{Natureza Enquanto Sujeito de Direitos}

Este tópico irá analisar a atribuição de direitos à natureza (Pachamama) pela Constituição Equatoriana, tida como a mais impactante novidade jurídica do atual diploma, bem como o princípio "buen vivir", considerado o marco teórico filosófico do Novo Constitucionalismo latino-americano. Tal análise é de suma importância, pois dignidade e direitos eram reservados somente aos seres humanos, predominando uma visão antropocêntrica da realidade.

$\mathrm{O}$ tratamento dado à natureza pelos povos indígenas é muito diferente daquele realizado pelo homem eurocêntrico e, como forma de rompimento desta colonização europeia, o Novo Constitucionalismo latino-americano positivou os direitos da natureza. No entendimento de Antônio Carlos Wolkmer:

(...) a Constituição Equatoriana rompe com a tradição constitucional clássica do Ocidente que atribui aos seres humanos a fonte exclusiva de direitos subjetivos e direitos fundamentais para introduzir a natureza como sujeito de direitos. Trata-se da ruptura e do deslocamento de valores antropocêntricos (tradição cultural europeia) para o reconhecimento de direitos próprios da natureza, um autêntico "giro biocêntrico", fundado nas cosmovisões dos povos indígenas. (WOLKMER, 2014, p. 76).

Neste mesmo sentido continua Antônio Carlos Wolkmer:

Possivelmente, o momento primeiro e de grande impacto para o "novo" constitucionalismo latino-americano vem a ser representado pela Constituição do Equador de 2008, por seu arrojado "giro biocêntrico", admitindo direitos próprios da natureza e direitos ao desenvolvimento do "bem viver". A inovação desses direitos não impede de se reconhecer os avanços gerais e o enriquecimento dos direitos coletivos como "direitos das comunidades, povos e nacionalidades", destacando a ampliação de seus sujeitos, dentre as nacionalidades indígenas, os afro-equatorianos, comunais e os povos costeiros. (WOLKMER, 2014, p. 82).

A "Madre Tierra" é considerada um ente vivo não apenas pelos andinos, mas também na visão científica. Desde tempos mais remotos que os pensadores da ecologia buscam atribuir direitos à natureza. Contudo, é somente com o Novo Constitucionalismo latino americano que se dá o giro ecocêntrico e os direitos da "Pachamama" ganham relevo e passam a ter efetividade no mundo dos fatos (FURLANETTO, 2014, p. 44).

A positivação dos direitos da natureza implica numa radical mudança nos conceitos de meio ambiente, desenvolvimento e justiça. Expressa um avanço de enorme importância e, que em um futuro próximo, estará presente em quase todas as Constituições. A atribuição de personalidade jurídica à natureza representa muito mais que uma proteção de cunho ambiental, pois para os povos ameríndios a "Pachamama" é uma divindade protetora. É o que ensina Antônio Carlos Wolkmer e Gabriela de Moraes Kyrillos:

Para além da própria explicação contida no texto constitucional, afirma-se que o termo Pachamama teria origem em um mito andino e faria referência à ideia de tempo, no sentido 
amplo que envolve a percepção de sua passagem, seu vínculo com a terra, com os períodos de colheita e com a própria vida dos seres que existem no universo. Essa concepção de tempo estaria ligada à língua "Kolla-suyu", mas que após o decorrer dos anos e o contato com outras etnias, seu significado sofre uma transformação e acaba por significar terra, que merecia culto. Nesse sentido, os índios chamavam sua divindade de Pacha Acachi, mas depois de ter contato com o colonizador espanhol, os indígenas a transformaram em Pacha Mama. Pachamama, tendo por base a filosofia ou cosmovisão indígena, deve ser compreendida como um ser vivo, com inteligência, sentimentos e espiritualidade, e que tem dentre seus elementos os seres humanos. (WOLKMER; KYRILLOS, 2015, p. 137).

A Constituição do Equador avança ao atribuir direitos próprios à natureza, independentes de qualquer valoração humana. Os componentes desse verdadeiro "mandato ecológico" estão representados na Constituição do Equador de 2008, nos artigos 71 a 74. Tais dispositivos indicam que a natureza ou Pachamama "tiene derecho a que se respete íntegramente su existencia y el mantenimiento y regeneración de sus ciclos vitales, estructura, funciones y procesos evolutivos". (GUDYNAS, 2011, p. 241). A "Pachamama" ultrapassa, assim, a posição de um simples objeto para se tornar sujeito de direitos (GUDYNAS, 2009, p. 37-38).

Seguindo com a inovação, os artigos mencionados reforçam os direitos da natureza através da previsão de sua restauração ou recuperação integral em caso de violação ou degradação, objetivando seu retorno ao estado anterior.

Ao colocar a "Pachamama" no centro de tudo, os direitos da natureza não deixam de incluir também os seres humanos. Os direitos da natureza não possuem por objetivo que os seres humanos não intervenham junto à natureza; o intuito é que os ecossistemas possam cumprir seus ciclos vitais (ACOSTA, 2011, p. 353-354).

Destaca-se, ainda, que em razão da atribuição de direitos à "Madre Tierra", qualquer pessoa poderá buscar a proteção da natureza no Poder Judiciário. Como a "Pachamama" passa a deter personalidade jurídica, qualquer indivíduo, comunidade ou povo poderá defender seus direitos.

O texto constitucional do Equador positiva, ainda, as expressões buen vivir e sumak kawsay para referir-se a uma vida em plenitude, em total conformidade com a "Pachamama". Tais conceitos representam uma ideia central na vida política desse país e possuem por referencia a noção de "bem viver" dos povos indígenas. Nos ensinamentos de Marilene Araujo:

Sumak kawsay ou suma qamaña são expressões utilizadas pelos povos indígenas originários da América. Os termos sumak e suma significam plenitude, sublime, harmonioso. Já o termo kawasay significa vida, ser, estado. Enquanto o termo qamaña significa viver, conviver. As duas expressões utilizadas para designar a vida com plenitude são traduzidas para o espanhol como buen vivir, ou seja, bem viver. Para os povos indígenas originários viver bem é saber viver e saber conviver de forma harmônica e equilibrada. Isto é, saber viver é estar bem consigo mesmo e saber se reacionar com todas as formas de existência. (ARAUJO, 2013, p. 260).

O "buen vivir" é um estilo de vida dos povos originários, baseado na harmonia e no equilíbrio das comunidades, das quais a natureza é parte integrante. Segundo Leonardo Boff, o "bem viver" é um objetivo positivado na Constituição Equatoriana e significa a harmonia entre todos os seres da "Pachamama" (BOFF, 2009).

Adotar o modelo do "bem viver" requer uma profunda mudança de pensamento dos seres humanos, eis que o postulado "busca romper com as visões clássicas do desenvolvimento associa- 
das ao crescimento econômico perpétuo, ao progresso linear e ao antropocentrismo". (GUDYNAS, 2011, p. 232). O "bem viver" exige "uma nova forma de conceber a relação com a natureza de maneira a assegurar simultaneamente o bem-estar das pessoas e a sobrevivência das espécies". (GUDYNAS, 2011, p. 231).

A Carta Política do Equador emprega o "buen vivir" com o sentido de ser, estar, fazer, sentir, viver bem, viver a plenitude, e não apenas no sentido de ter ou possuir. Para ele "sumak kawsay" significa: "suprir as necessidades, ter uma vida digna com qualidade, bem como uma morte, poder amar e ser amado, um florescimento de todos em harmonia e paz com a "naturaleza", possuir tempo livre para contemplar e se emancipar" (GALLEGOS, 2010, p. 08).

Como princípio constitucional, o "buen vivir" surge para orientar a efetivação e a concretização de toda a Constituição e de toda a ordem jurídica fundamental do povo equatoriano. $\mathrm{O}$ texto constitucional faz menção ao "buen vivir" em seu preâmbulo e trata também dos "derechos del buen vivir", que são: água e alimentação (artigos 12 e 13), ambiente sadio (artigos 14 e 15), comunicação e informação (artigos 16 a 20), cultura e ciência (artigos 21 a 25), educação (artigos 26 a 29), habitat e vivenda (artigos 30 e 31), saúde (artigo 32), trabalho e seguridade social (artigos 33 e 34).

Como já dito, uma das consequências mais importantes da adoção do princípio do "bem viver" é a atribuição de diretos à natureza (Pachamama). Todos os seres vivos, como partes integrantes da natureza, seriam titulares de direitos. No próximo tópico analisar-se-á o primeiro processo judicial em que se reconheceu a natureza enquanto sujeito de direito e garantiu-se sua proteção e regeneração com base nos postulados do "buen vivir".

\section{O caso do Rio Vilcabamba:}

Conforme o exposto acima, a maior novidade jurídica encontrada na Constituição do Equador de 2008 é a possibilidade de que a natureza (Pachamama) seja sujeito de direitos e não mais objeto. Nela, a norma do artigo 10 reconhece a natureza como titular de direitos, nos seguintes termos:

\footnotetext{
Artigo 10: Las personas, comunidades, pueblos, nacionalidades y colectivos son titulares y gozarán de los derechos garantizados em la Constitución y em los instrumentos internacionales.
}

La naturaleza será sujeto de aquellos derechos que le reconozca la Constitución. (grifo nosso).

Tanto é assim que a primeira ação proposta com base neste artigo tem como parte um rio, o Rio Vilcabamba. É o primeiro exemplo de reconhecimento judicial dos direitos da natureza.

Trata-se da Ação Constitucional de Proteção à Natureza proposta na província de Loja, no Equador, julgada em 30 de março de 2011, pela Corte Provincial de Justiça de Loja (Juicio 111212011-0010). A ação tinha por objeto a degradação do Rio Vilcabamba, importante fonte de subsistência para a população local.

No caso, o Governo da Provincial de Loja utilizou o Rio Vilcabamba como depósito de materiais de escavação (areia, cascalho, árvores, etc.), oriundos da construção de uma estrada entre as cidades de Vilcabamba e Quinara. A obra, no entanto, estava acontecendo sem nenhum tipo de 
estudo prévio de impacto ambiental ou social. Com a chegada das chuvas, no período de março a abril de 2009, as águas do rio aumentaram. A soma dos eventos, depósito de material poluente aliado à grande quantidade de chuva, causou sérios danos ao meio ambiente e aos moradores locais, tais como enchentes nos terrenos à margem do rio, destruição da fauna e da flora aquáticas, entre outros problemas (MORAES; FREITAS, 2011, p. 117).

Por conta desses eventos, dois americanos proprietários de terras situadas às margens do rio ajuizaram, em 07 de dezembro de 2010, uma "Acción de Proteción" aos direitos da natureza, ação constitucional destinada à proteção de direitos previstos na Constituição do Equador, ameaçados por ação ou omissão de autoridade pública não judicial, nos termos do artigo 88 do referido diploma, in verbis (GUSSOLI, 2014, p. 3):

Art. 88. La acción de protección tendrá por objeto el amparo directo y eficaz de los derechos reconocidos em la Constitución, y podrá interponerse cuando exista una vulneración de derechos constitucionales, por actos u omisiones de cualquier autoridad pública no judicial; contra políticas públicas cuando supongan la privación del goce o ejercicio de los derechos constitucionales; y cuando la violación proceda de una persona particular, si la violación del derecho provoca daño grave, si presta servicios públicos impropios, si actúa por delegación o concesión, o si la persona afectada se encuentra en estado de subordinación, indefensión o discriminación.

Apesar de constar como autores duas pessoas físicas, a análise do caso indica que o sujeito interessado da ação era o Rio Vilcabamba, representado judicialmente por indivíduos, já que o próprio artigo 71 da Constituição Equatoriana dá legitimidade processual a qualquer pessoa para a defesa do meio ambiente e reconhece a natureza como sujeito de direitos, vejamos: "toda persona, comunidad, pueblo o nacionalidade podrá exigir a la autoridad pública el cumplimiento de los derechos de la naturaleza". (GUSSOLI, 2014, p. 03).

E foi com base nesse artigo 71, que garante os direitos de La Madre Tierra (Pachamama) e reconhece a natureza como sujeito de direitos, que o juiz da Corte Provincial de Loja fundamentou sua decisão. Diz o julgado: "dada a indiscutível importância da Natureza, e tendo em conta como fato notório seu evidente processo de degradação, a Ação de Proteção resulta na única via idônea e eficaz para por fim e remediar de maneira imediata um dano ambiental focalizado". (MORAES; FREITAS: 2011, p. 117).

O julgado esclarece ainda que: "é aberrante o Governo Provincial, sendo a autoridade ambiental local, não cumprir a sua obrigação de proteger o meio ambiente, chegando ao extremo de construir uma estrada sem licença e estudo de impactos ambientais". E finaliza concluindo que: "quando do choque de direitos coletivos, prevalecerão os direitos da Natureza, até mesmo por abranger uma maior coletividade, como também gerações futuras". (MORAES; FREITAS, 2011, p. 117).

O Tribunal, no dispositivo da decisão, fez as seguintes recomendações ao Governo de Loja: realizar a limpeza do solo contaminado; encontrar outro local para o despejo dos materiais oriundos das escavações; sinalizar o local de construção da estrada; apresentação de um plano de reabilitação das áreas do rio e das propriedades que foram degradadas; e, por fim, apresentar um estudo de impacto e permissão ambiental para construção da estrada (MORAES; FREITAS, 2011, p. 118). 
Da análise das recomendações, pode-se perceber que no Equador, toda medida está voltada à restauração do meio ambiente afetado. O direito à restauração da "Pachamama" previsto na Constituição afasta qualquer forma de indenização para se compensar um dano ambiental.

No entanto, mesmo após a referida decisão judicial, o cenário pouco se alterou. Tanto que um ano após o julgamento, o Governa ainda não possuía licença ambiental para construir a estrada, poucas medidas de reabilitação haviam sido tomadas e os escombros do rio não tinham sido retirados (GUSSOLI, 2014, p. 05).

Ao analisar a atual Constituição do Equador, especialmente os artigos 71 e 72, verifica-se que há direitos da natureza a serem respeitados, seja no tocante à sua existência e proteção, seja nos aspectos ligados à sua regeneração. A natureza, assim, não é mais vista como objeto, mas sim como sujeito, e possui ao menos esses três direitos listados na Carta Constitucional: direito à existência, à integridade e à regeneração em caso de dano (GUSSOLI, 2014, p. 16).

Diante do referido caso judicial, vê-se a importância do reconhecimento constitucional dos direitos da natureza. E, foi no inovador constitucionalismo ecocêntrico do Equador que se positivaram, pela primeira vez na história, elementos da cosmovisão andina, Pachamama e o "buen vivir", inerentes à relação dos indivíduos com a natureza. Nas palavras de Germana de Oliveira Moraes e Raquel Coelho Freitas:

Os direitos humanos hão de ser exercidos de maneira a que sejam também assegurados os direitos de Pachamama, visto que os seres vivos, inclusive os humanos, compõe um só ser e, ferindo-se os direitos de um ser que abrange todos os outros, está por se violar de morte toda a coletividade humana. Somos todos irmãos e irmãs, filhos e filhas da mesma Mãe Terra. Assim, inaugura-se uma nova fase em que se repensa o direito, com novas bases, a partir de uma concepção na qual a Natureza (Pachamama) é o centro, sujeito prioritário de direitos e de dignidade. (MORAES; FREITAS, 2011, p. 118).

Conclui-se, assim, que embora não tenha havido o cumprimento integral da decisão, o caso é de grande relevância para o mundo moderno, eis tenha sido a primeira vez que se presenciou um rio atuando judicialmente na busca da efetivação de direitos seus constitucionalmente reconhecidos.

\section{Considerações finais}

O Novo Constitucionalismo latino-americano nasce na região dos Andes a partir das reivindicações de parcela da população (indígenas, negros, afrodescendentes, etc.) que era deixada de lado por parte do Estado. A partir deste inconformismo, inúmeras mudanças ocorrem, tais como maior participação popular dos grupos excluídos nas decisões políticas, ampliação do rol de direitos positivados em prol desta camada social, reconhecimento do pluralismo jurídico e da justiça indígena, entre outros. Seu objetivo é realizar uma ruptura com o colonialismo eurocêntrico que dominou a região por séculos, com a proposta de refundar o Estado.

As Constituições que mais representam este novo constitucionalismo são os Textos Políticos do Equador (2008) e da Bolívia (2009).

Analisando o contexto da evolução histórica desse novo modelo de constitucionalismo, com enfoque especial ao fenômeno ocorrido no Equador, pode-se concluir pela importância do movi- 
mento que culminou com a reformulação do Estado, priorizando a diversidade cultural de seus povos, rompendo em definitivo com o colonialismo eurocêntrico

Além das significativas mudanças de caráter democrático, a Constituição do Equador de 2008 incorporou a cosmovisão indígena no texto constitucional equatoriano, trazendo consigo o reconhecimento de dois inovadores princípios: o Buen Vivir e a natureza enquanto sujeito de direito, e institucionalizou o modelo ecocêntrico, em oposição ao antropocêntrico, atribuindo direitos e personalidade jurídica a "Pachamama" (direitos da natureza).

O povo indígena possui uma forte relação com a "Naturaleza" e todos os seus seres. Para eles, a mesma deve ser vista como um ser vivo e não apenas como um objeto. A atribuição de direitos decorre desta visão respeitosa com a "Madre Tierra" em busca da sua proteção diante de inúmeras lesões ambientais em que está passível na atualidade. Por isso, a incorporação do "buen vivir" no texto constitucional visando sustentar os direitos da natureza.

A partir dessa positivação, elaborou-se o presente trabalho com o objetivo de verificar se a inovação trazida pela Constituição Equatoriana, atribuição de direitos à natureza, estava sendo efetivamente cumprida na prática, com sua plena reabilitação e restauração quando violada. Para isso, analisou-se o primeiro processo judicial em que a natureza figurou como parte, conhecido como caso do "Rio Vilcabamba". O direito à restauração da "Pachamama" previsto na Constituição afasta qualquer forma de indenização para se compensar um dano ambiental. No Equador, toda medida será voltada à restauração do meio ambiente afetado.

Concluiu-se, no entanto, que as decisões judiciais reconhecendo os direitos da natureza não estão sendo integralmente cumpridas na prática, apesar da grande relevância do assunto para o mundo moderno. $\mathrm{O}$ caso aqui analisando foi pioneiro na temática, pois foi a primeira vez que se presenciou um rio atuando judicialmente na busca da efetivação de direitos seus constitucionalmente reconhecidos.

\section{Notas}

1 Pós-Doutor em Direito Civil, com bolsa de pesquisa PNPD/CAPES, na Universidade do Vale do Rio dos Sinos - UNISINOS (2014). Doutor em Direito Civil na Universidade Federal do Rio Grande do Sul - UFRGS (2013). Mestre em Ciências Criminais pela Pontifícia Universidade Católica do Rio Grande do Sul - PUCRS (2007). Especialista em Ciências Penais pela PUCRS (2005). Pós-graduação pela Escola da Magistratura do Rio Grande do Sul - AJURIS (2003). Graduado em Ciências Jurídicas e Sociais pela PUCRS (2002). Atualmente, é Professor da Graduação e Pós-Graduação da Faculdade de Direito da Universidade do Extremo Sul Catarinense - UNESC e da Pós-graduação do Centro Universitário Ritter dos Reis - Uniritter. Parecerista em diversas revistas. Participante em diversos projetos de pesquisa vinculados à PUCRS e UFRGS. Pesquisador do Núcleo de Pesquisas em Direitos Humanos e Cidadania - NUPEC, na UNESC. E-mail: gustavoborges@hotmail.com

2 Possui graduação em Direito pela Universidade do Extremo Sul Catarinense (2009). Possui duas PósGraduações Lato Sensu uma concluída em 2011 - Especialização em Preparação para a Magistratura Estatual, e a outra concluída em 2012, na área de Direito Constitucional. Atualmente é Tabeliã e Registradora da Escrivania de Paz do Distrito de São Bento Baixo, Município de Nova Veneza/SC. Tem experiência na área de Direito, com ênfase em Direito Público. E-mail: mahmlc@hotmail.com 
O novo constitucionalismo latino-americano e as inovações sobre os direitos da natureza na constituição equatoriana BORGES, G. S.; CARVALHO, M. M. L. C. de. F.

\section{Referências}

ACOSTA, Alberto. Los derechos de la naturaleza: una lectura sobre el derecho a la existencia. In: ACOSTA, Alberto; MARTÍNEZ, Esperanza (Comps.). La naturaleza con derechos: de la filosofía a la política. Quito: Abya-Yala, 2011.

ARAUJO, Marilene. O Buen Vivir na Constituição do Equador. Revista de Direito Constitucional e Internacional, 2013.

ÁVILA SANTAMARÍA, Ramiro. El neoconstitucionalismo Transformador: El estado y el derecho en la constitución de 2008. Quito: Abya-Yala, 2008.

BOFF, Leonardo. O viver melhor ou o bem viver? Disponível em: http://www.terrazul.m2014.net/spip. php?breve239 . Acesso em: 25 de jun. 2017.

DUSSEL, Enrique D. Filosofia da Libertação na América Latina. 2. ed. São Paulo: Editora Unimep e Loyola, 1977.

EQUADOR. Acórdão na apelação cível número 11121-2011-0010 do Juzgado Tercero de lo Civil de Loja. Relator Luis Sempértegui Valdivieso. Equador, Loja.30. mar. 2011. Disponível em: http://www.elcorreo. eu.org/IMG/pdf/Sentencia_ce_referencia.pdf.

. Constituição (2008). Constituição da República do Equador: promulgada em 28 de setembro de 2008. 218 f. Disponível em: http://biblioteca.espe.edu.ec/upload/2008.pdf

FURLANETTO, Taísa Villa. O Constitucionalismo Transformador Latino-americano: implicações na restauração e reparação do dano ambiental. Caxias do Sul, 2014.

GALLEGOS, René Ramirez. Socialismo del sumak kawsay o biosocialismo republicano. Rebelión. [online]. Disponível em: http://www.rebelion.org/noticia.php?id=116667 . Acesso em: 25 jun. 2017.

GRIJALVA, Agustín. El Estado plurinacional e intercultural en la Constitución ecuatoriana de 2008. In: Pueblos Indígenas constituciones y reformas politicas en América Latina. 1 ed. Lima: Raquel Z. Yrigoren Fajardo Editora, 2010.

GUDYNAS, Eduardo. La ecología política del giro biocéntrico en la nueva Constitución de Ecuador. Revista de Estudios Sociales, Bogotá, n. 32, abril 2009.

. Los derechos de la Naturaleza em serio. Respuestas y aportes desde la ecología política. Bogotá, 2011.

GUSSOLI, Felipe Klein. A natureza como sujeito de direito na Constituição do Equador: considerações a partir do caso Vilacamba. Disponível em: http://www.direito.ufpr.br/portal/wp-content/uploads/2014/12/ Artigo-Felipe-Gussoli-classificado-em-1\%C2\%BA-lugar-.pdf . Acesso em: 08 jul. 2017.

MAGALHÃES, José Luiz Quadros de. O estado plurinacional e o direito internacional moderno. Curitiba: Juruá, 2012.

MARTÍNEZ DALMAU, Rúben. La Paz, Quito e Caracas recriam constitucionalismo latino. Disponível em: http://www1.folha.uol.com.br/fsp/mundo/ft0103200909.htm . Acesso em: 18 jun. 2017.

; VICIANO PASTOR, Roberto. O processo constituinte venezuelano no marco do novo constitucionalismo latino- americano. In: WOLKMER, Antônio Carlos; MELO, Milena Petters. Constitucionalismo latino - americano: tendências contemporâneas. Curitiba: Juruá, 2013.

MORAES, Germana de Oliveira; FREITAS, Raquel Coelho. O Novo Constitucionalismo Latino-americano e o Giro Ecocêntrico da Constituição do Equador de 2008: os Direitos de Pachamama e o Bem Viver (Sumak Kawsay). Ceara: Editora da Imprensa da Universidade do Ceará (UFC), 2011.

PANIKKAR, Raimon. Religión, filosofia y cultura. Disponível em: http://them.polylog.org/1/fpr-es.htm Acesso em: 20 de jun. de 2017.

SANTOS, Boaventura de Sousa. Refundación del Estado en América Latina: perspectivas desde uma epis- 
temología del Sur. Lima (Peru): GTZ e Fundación Ford, 2010.

Cuando los excluidos tienen Derecho: justicia indigena, plurinacionalidad e interculturalidad. In: SANTOS, Boaventura de Sousa; JIMÉNEZ Agustín Grijalva. Justiça indígena, plurinacionalidad e interculturalidad en Equador. Quito: Fundación Rosa Luxemburg/Abya Yala, 2012.

WOLKMER, Antônio Carlos. Introdução ao Pensamento Jurídico Crítico. $6^{\text {a }}$ ed. São Paulo: Saraiva, 2008. . Pluralismo crítico e perspectivas para um novo constitucionalismo na América Latina. In: WOLKMER, Antônio Carlos; MELO, Milena Petters. Constitucionalismo latino - americano: tendências contemporâneas. Curitiba: Juruá, 2013.

Ética da sustentabilidade e direitos da natureza no constitucionalismo latino-americano. In: LEITE, José Rubens Morato; PERALTA, Carlos E. (orgs). Perspectivas e desafios para a proteção da biodiversidade no Brasil e na Costa Rica. Editora Instituto o Direito por um Planeta Verde, 2014.

; FAGUNDES, Lucas Machado. Para um novo paradigma de estado plurinacional na América Latina. Revista NEJ - Eletrônica, Vol. 18 - n. 2, 2013.

; KYRILlOS, Gabriela de Moraes. Redefinindo os paradigmas do direito na América Latina: interculturalidade e Buen Vivir. Revista de Direito Ambiental. Vol. 78, ano 20. São Paulo: RT, 2015 